\title{
Pulmasõnastik IV
}

\section{$\underline{\text { Ülo Tedre }}$}

tanu lööma, ka tanule lööma (Muh); väike tüdruk (u 10-aastane) lööb tanutatud noorikut (kolm korda); vanemas kihistuses ütleb ka tanutamissõnad, tasuks saab noorikult paelad.

tanu näitamine (Rid) tanutatud nooriku näitamine pulmalistele (kutsumata külalistele) raha eest. Vt tanu vaatamine.

tanu panija (Lüg) vt tanutaja.

tanuraha (Ran), ka tanutamise raha, tanuvaatamise raha. Vt tanu vaatamine.

tanutaja isik sõltus tanutamise kohast: kui tanutati mõrsjakodus, oli tanutajaks kaasanaine või kõrvane (harva oma ema, vististi hilisem ilming); kui peiukodus, siis peiuema või isamehe naine (harva isamees); uuemaks ilminguks (ja peamiselt Kagu-Eestis) on tanutaja koolmeister; erandlikult on mainitud ka tanutamist kirikus pastori poolt.

tanutamine vt ka linutama (Põhja-Eesti); pulma kui siirderiituse tipphetk - mõrsja varustamine naisele tunnuslike riideesemetega, sellega muutus mõrsja noorikuks (kelleks jäi kuni esimese lapse või esimese poja sünnini). Tanutamine toimus kas mõrsjakodus (LääneEesti) või peiukodus, enamasti pulmaliste eest varjul (alles hilisemas kihistuses, kus tava rituaalsust hakkab asendama mängulisus, tehakse seda avalikult, pulmaliste juuresolekul), mõrsja istus kas peiu kõrval või üksi (veimekirstul), tanu pandi pähe kolmel korral (tanu raputas maha mõrsja ise või lükkas peiupoiss mõõgaga), enne pähepanemist andis tanutaja (tanuga) löögi mõrsja põsele; tanutamist saatsid nn tanutamissõnad. Tanutamisele järgnes kohe põlletamine (enamasti ongi tanutamise all mõeldud nii tanu pähe asetamist kui ka põlle ette sidumist). Tanu oli abielunaise tunnus, tüdruk ei tohtinud tanu kanda (lapsega tüdruk tanutati vanemate naiste poolt mõnitaval moel).

tanutamissõnad loits, mis lausuti mõrsja tanutamisel: «Pea tanu peas, pea tanu peas / unuta uni, mäleta mälu / ää jättig mehe külje alla» (Muh); «Unusta uni, mäleta mälu, pea mees meeles» (Põhja-Eesti); «Unusta uni, tuleta tuli, pea meeles mehe kaltsõ» (Lõuna-Eesti).

tanu vaatamine (Emm, Rei) nooriku tanu - s.o tanutatud nooriku - vaatamine raha eest. Vaatajaks on kas pulmalised või lapulised. Vt tanu näitamine, ka tanuraha.

tanuviin (Hel) pärast tanutamist joodav viin (raha eest). Vt terviseviin.

tedre laskmine (Trv, Lai) pulmanali.

tee kinnipanemine külanoored tõkestasid pulmarongi (vt pulmarong) tee ja nõudsid passi. Passiks oli õlu, uuemal ajal viin; on tehtud ka «pulmapasse» (vt pulmapass). Tõkkeks on teele kuhjatud esemed või lõke või üle tee tõmmatud köied. Heade hobustega püüti ka tõkkest üle või läbi kihutada, mõnikord see õnnestus. 
teine peiupoiss (Rap) teine peiupoiss kandis hoolt peiu eest (esimene peiupoiss jälgis mõrsjat).

teised viinad suured viinad ehk kosjad.

tervise viin (Lüg, Lih, Vil, Ksi, Ran, Võn) rahakogumise komme, tavaliselt toimus pärast tanutamist, isamees kallas viina klaasidesse ja kutsus pulmalisi noorpaari terviseks jooma, kes jõi - see viskas laual asuvasse taldrikusse raha (jõukamad rubla, vaesemad münte). Vrd laua otsa viimine, pealisjoot, kirstupära raha kogumine.

titeristimine (Pha) pulmanali või -mäng.

tititupp (Plt) annivakas kõige peal oli munnide kott, mida nimetati tititupp, see oli esimene annetus peiule - kui noormees kuhugi sõitma pidi, siis jättis oma asjad titituppe, et teiste juurde ei lähe. Naljaks kujunenud tava.

toapühkimine (Kuu, Rap, Mär, Var, Khn, MMg) rahakogumise komme pulmades, vt põranda pühkimine. Kesk-Eestis on pühkijaks olnud peiupoiss (Kuu) või pulmatüdrukud (Rap, Mär) - mõrsjakodus pruuttüdrukud, peiukodus peiutüdrukud.

tohilakk kosjasobitaja, meesterahvas.

tooritanu valge noorikutanu, ainult pulma-ajal kantav.

trummilöömine (Kod) pulmamäng.

truuska (Vas, Se) sajavanem, raudkäsi. On peategelane pulma kutsumisel, saadab pulmasõitudel, viib noorpaari magama, kaitseb aset.

tubakõd (Se) kosjad.

tuba pühkima (Var, $\mathrm{MMg}$ ) raha koguma (kolmanda pulmapäeva hommikul noorik pidi magamisõlgi luuaga $\sim$ vihaga välja pühkima, pulmalised loopisid õlgedesse raha). Vt põranda pühkimine, toapühkimine.

tuhahoidja (Trv, Hel) pulmategelane, kes jälgis 1. et tuhka ei saadaks leelt nägemata ära võtta (maagilisteks, noorpaari kahjustavateks tegemisteks); 2. liha küpsetamist $\sim$ küpsemist.

tuhakott (Krk, Räp) pulmategelane, kes istus kogu aja kolde või lee ees kirvega; ta pidi valvama tuha järele (vt tuhahoidja 1) ja selle järele, et keegi leelt tuld ei võtaks (ka piibu peale mitte) - see pidi noorpaari kahjustama; tuhakott pidi olema eelviimane või viimane laps.

tuhavaht (Pal) vt tuhahoidja 1 .

tuhkapuss (Kar) vt tuhahoidja 1. 
tuhkmunn (Hls) vt tuhahoidja 1 (mees, kes valvab - tuhalabidas käes, et tuhka ära ei kaetaks, siis kaoks tuha vägi ja pesu ei saa pesemisel valgeks). Siin on viide leelisega (s.o lehtpuutuhaga) pesemisele.

tulekahju kustutamine (Ha) rahakogumine: taldrikule valatakse viina ja süüdatakse põlema, isamees kutsub pulmalisi tulekahjut kustutama, seda tehakse taldrikule visatava rahaga.

tulesaba vt isamees.

tundur lapuline, kontvõõras.

tupetaat $(\mathrm{Kse})$ isamees.

tutilinnud (Jür) pruuttüdrukute nimetus.

tuttpaelad (Vig) veimede osa, mida noorik pidi uue kodu tutvustamisel jagama.

tõkked vt tee kinnipanemine. Tõkked tehti kirikuteele minnes $\sim$ tulles ja mõrsjakodunt peiukoju sõites. Algselt oli tõketel ilmselt maagiline tähendus, hiljem kujunes naljaks - joogi norimiseks.

tõmbamine vägivaldne naise röövimine, esines veel XIX sajandi algul; enamasti toimus tõmbamine noorte kokkuleppel, põhjuseks vanemate (eriti neiu vanemate) vastuseis abielule. Tõmbaja - peig - pidi koos tõmmatuga - mõrsjaga - teatava aja varjus olema (aeg olenes kohast, samuti ajastust); kui neid selle aja jooksul ei leitud, siis loeti toimunu kehtivaks ja abielu sõlmituks (lugu võis päädida ühepoolse pulmaga). Kui paar leiti, viidi neiu tagasi koju, noormees aga kohtusse (varasemal ajal löödi ka maha), kus teda vastavalt karistati.

tõotus vt veimed.

tõrretants (Muh) meestetants pulmas: parem jalg tõrre peal, hüpatakse ühel jalal ümber tõrre, oli kasutusel veel XX saj alguses.

tõstekindad (Tõs, Pär). Kui pulmarong jõuab peiu koju, tuleb äi ja tõstab mõrsja saanist tõstab tuppa ja saab tasuks paari kindaid; need on tõstekindad.

tõstetoop (Koe). Kui kosjaviina viimas e pulma kutsumas mõrsja tuppa tuli, tõsteti ta kolm korda üles - õnneks ja uue elu eduks; mõrsja andis perele tõstetoobi s.o kosjaviina.

tõstmine (Muh) pulmalistest kindlamalt paari hoidev poiss-tüdruk tõsteti hurraa-hüüdega üles ja n-ö pandi paari; poiss andis tõstjatele raha.

tähevalgjatsed, ka tähevalgjad (Plv) 1. abiellujate kokkusaamine, et määrata pulma aeg; 2. kingituste jagamine pulmas (peamine tähendus); 3. kitsama sugulasteringi kokkutulek teisel pühapäeval pärast pulmi noorpaari juures, vt järelpulmad.

tähtraha (Se) kosija poolt kositava emale antav raha, vrd käsiraha. 
tähtraha rätt (Se) rätik, mille vahel on tähtraha, pistetakse märkamatult laudlina alla.

tähträtt (Räp) vt tähtraha rätt.

täied anded, ka täied annid (Mus, Ksi): tavaliselt sukad sokid ja kindad vööga või sukapaeltega kokku seotud; äiale-ämmale mõeldud täied annid sisaldasid veel särgi (taskurätiku) ja vöö.

tönk (Khn) maskeeritud, täpsemalt, kostümeeritud pulmategelane - naljamees.

uig (Var, Krj, Ans, Kaa, Vll, Khn) tavaliselt valge linane linik, millega kaeti mõrsja pea (ja ülakeha) pulmasõitudel; algne põhjus oli varjata mõrsjat kadeda silma ja ülepea võõra, vaenuliku jõu eest; hilisem seletus oli, et mõrsja ei leiaks koduteed; uig kinnitati kolme või enama (5-7) preesiga eest ja peapaelaga; mõrsja katjaks oli reeglina kõrvane või kaasanaine. Vt ka $\underline{s o \tilde{b} a}$ ja $u j u$.

uju (Iis, VNg, Rap, Vig, Var, Han, Kse, Lih, Kir, Mar, Rid, Khn, Tõs, Aud, Mih, PJg, Hää, Saa, Nõo, Urv) pruudirätik, vt uig.

ujualune (Aud) uig.

uju heitmine komme eelneb vahetult tanutamisele (vt tanutamine), on selle osa: lauas istuval mõrsjal võtab isamees mõõga otsaga uju peast, keerutab seda mõõgaotsas (kolm korda) ja viskab siis ära.

ujule saama (Muh) mõrsjaks saama.

ujulina (Muh) hilisem kombekihistus: pandi tanu peale (vt ujutanu) nii, et teine (parem) silm jäi katmata; ujulina oli otsekui tanu jätk.

ujunaised (Kse) pulmategelased, tegevad mõrsja viimise ajal, uju hoidjad.

ujunarts (Kul, Vig) vt uig või uju; ebamõrsjad kaeti peiule esitamisel ujunartsuga raskendamaks nende äratundmist.

ujurätik (Mar) rätik, mis mõrsjal laulatamise ajal peas oli.

ujutamine (LNg, Tõs, Mih, PJg) mõrsja katmine ujuga enne sõitmist, ilmselt vana pulmakomme.

ujutanu (Muh) mõrsja peakate, mida kanti uju all; hilisem kihistus vanast kombest.

ujutüdruk (Kir) peiupoolsete pulmarongiga kirikusse sõitva peiu kõrval istuv tütarlaps (u 815-aastane), n-ö mõrsja asendaja või esindaja, oli ujuga kaetud.

umbruk, ka umbrukas (Khn, Tõs) 1. pruutneitsi, mõrsja saatja; 2. noor tüdruk-talitaja, kes koristab tuba, toob sööki lauale, koristab laua jne, neid on nii mõrsja pool kui peiu pool (u 4$5)$. 
uru-nui (Plv) pulmategelane - vana naine -, kes tuleb koos mõrsjaga peiukoju ja läheb koos noorpaariga pulmaööl aset jagama (mõnel pool teeb seda isamees), ilmselt vana komme, mis hiljem on muutunud robustseks naljatluseks.

uue kodu tutvustamine vt ka valget viskama 3 ja valgustama; põline tava, mis järgneb enamasti vahetult mõrsja peiukoju saabumisele, kohati ka esimesele söömisele peiukodus, kombes osalevad mõrsja ja peiuema, kombe sisuks on mõrsja tutvustamine uue kodu ja majapidamisega, eriti perenaisele oluliste objektidega (kaev või veevõtu koht, lee või kolle, aidad, laut, heinaküün, kangaspuud, vokk, loomadest tutvustati-näidati eeskätt neid loomi, mis jäid uue perenaise hooldada); igale tutvustatavale objektile pidi mõrsja jätma andeid (vöö, paelad) - anded jäid vanaperenaisele; seda nimetati uue kodu valgustamiseks. Ilmselt hilisem on tava anda esemete asemel raha. Tavas võib näha iidset ohverdamist majahaldjale, kindlustamaks selle heatahtlikkust uue kodakondse vastu. On teateid, et vastumeelse mõrsja puhul on ämm püüdnud teda seada piinlikusse olukorda, näidates hoopis rohkem objekte kui tava järgi vajalik (nt kukke, kassi jts) - viimases hädas on siis mõrsja tõmmanud oma sukapaelad ära ja visanud need kukele $\sim$ kassile kaela.

vaadiline (Krl, Har, Rõu, Vas) lapuline (enamasti naisterahvas), kes tuleb mõne nõuga, milles piim või muu toidukraam, neid kostitab raudkäsi mõrsja emalt saadud viinaga; süüa vaadilistele ei pakuta, nad osalevad tantsul (ja mängudes).

vaadirahvas (Har) vt vaadiline.

vaadivedaja $(\mathrm{Krl})$ vt vaadiline.

vaadi vitsutamine (Pär) üks rahakogumise kombeid pulmades, lokaalne.

vaatajad (Käi, Rei) nugijad ehk lapulised.

vaatamine (Saa) vt kuulamine; peiu ema või isa käis salaja kositava juures uurimas, kas neiu vanemad on nõus kosjadega; vaatamise juurde ei kuulunud kuuluviin, oli kuulamise kas väljaarenemata või juba degenereerunud vorm, ilma rituaalsuseta.

vagapulm (Mus) pulma kolmas päev, mille õhtul mindi lahku: mõrsjapoolsed mõrsjakoju, peiupoolsed jäid peiukoju, sellega lõppesid kaheotsaga pulmad.

vaka-anne (Mus) pruudianded, mida kõrvane vakast peiu sugulastele jagab teisel pulmapäeval.

vakajägaja (Mar, Mus, Khk, Muh) kõrvane (kui ta andeid jagab).

vakajägu (Emm) vaka jagamine.

vaka lahti laulmine (Khk) laulmine enne vaka jagamist, laulmise ajal võtab ninamees (vt ninamees) kepiga veimekirstu pealt sinna laotatud valge lina. 
vakalaud (Vas, Se) laud, mille taga sööb vakarahvas peigmehe pool (sajarahvas ei istu vakalauas). Oli põline tava, et «sissesõitnud» pulmalised said enne süüa (nii suurt lauda ja ruumi ei olnud, et kõik pulmalised oleksid mahtunud korraga sööma).

vakalaul (Khk) laul(ud), mida lauldi vaka jagamisel.

vaka müümine või ostmine (Vig) metafoor andide eest antava raha kogumise kohta.

vakanaised (Plv, Vas, Se) 1. mõrsjapoolsed pulmategelased, kes sõitsid vakaga kaasa; oli tavaks näidata vakanaistele karjamaad; 2. mõrsja sugulased.

vakapoisid (TMr, Ote, Rõu, Räp, Vas, Se). Vakk ehk veimekirst tuuakse pulmarongi eesotsas, kirstul istuvad toojad ehk vakapoisid (tavaliselt neli), kaks kaasikut kõrval; vakapoistele pakuti saabumisel sõira. Vaka viimine oli auasi.

vakapäev (Võn, Rõu, Plv, Vas, Se) teine pulmapäev; päev, millal veimekirst peiukoju tuuakse.

vakaraha (Lüg, Koe, Käi, Emm, Ksi) 1. andide eest kingitav raha; kohati oli tavaks, et andsid ainult need, kes said täied annid; mõnikord on kujunenud omaette rituaaliks: isamees istub laua taga, õlleklaasid ees, peiupoisid toovad pulmalisi paarhaaval isamehe ette, järgneb pärimuslik dialoog (nime küsimine, pulma kutsumine jne), siis isamees pakub õlut, pärast joomist viskab jooja mündi õlleklaasi (vrd lemmkibu), siis antakse talle veimekimp; 2. lokaalselt tuntud: pruudi poolt pastorile antav raha.

vakarahvas (Ote, Plv, Rõu, Räp, Se) 1. pruudipoolsed pulmalised; 2. need, kes tulid teisel pulmapäeval veimevakaga $\sim$ veimekirstuga peiukoju.

vakasõit (Rõu) mõrsjapoolsete pulmaliste sõit peiukoju koos vakaga, kõige ees veljed.

vakatants (Lüg, Krk) 1. lahjade saaja hüppas kolm korda õhku, hüüdes «aitüma» (PõhjaEesti); 2. pärast andide jagamist tantsiti, anded kaelas.

vaka välja või lahti tantsitamine (Ris, Phl, Käi) 1. kui andevakk tuppa toodi, tantsis peiupoiss või veli (pruudivend) kolm korda ümber vaka ja asetas selle siis lauale; 2. kirstumees või sajanaine tantsitavad annete saaja sajavanema ja peiu ette (kes istuvad kõrvu), järgneb taas pärimuslik dialoog (küsitakse passi või kirja), pärast raha panemist ja annete saamist tantsib andeid jaganud mõrsjaga.

vakatruuska (Se) vt mõrsjatruuska.

vakavanem (Rõu, Räp) pulmategelane mõrsjapoolsete pulmaliste seas, vanem (abielus) mees: sõidab vakasõidul kõige ees, toob mõrsja lauluga saja tarre, on mõrsja selja taga tanutamisel. 
vakk (Ris, Mar, Phl, Käi, Mus, Khk, Jäm, Jaa, Muh, Rõu, Vas, Se), ka andevakk, annivakk, kirstvakk, mõrsjavakk, pruudivakk, saadivakk, veimevakk; 1. puulaastudest vakk, millega toodi kirstust andeid pulmalistele jagamiseks; 2. ülekantud tähenduses ka veimekirst (koos sisuga); 3. ka mõrsjapoolne pulmarahvas ehk vakarahvas (Se).

vakka ajama (Jäm) pulmas andeid koguma.

vakka korjama (Phl) pulma kutsumise (vt pulma kutsumine) ja hundihänna ajamisega (vt hundihända ajama) veimevakka täitma.

valenoorik (Var, Tõs) vt valtsnoorik.

valepruut (Mus) vt valtsnoorik.

valestama (Kod) peiupoolseid pulmalisi ehtima mõrsjakodus vööde ja linikutega; käetüdrukud ja mõrsjapoolsed pulmalised tõid linikuid kaasa (kui oli teada, et neid mõrsjal ei jätku) ja aitasid neid üle õla siduda; kui linikuid jätkus, siis ehiti nendega ka vakarahvast, aga ainult paarilisi, käetüdrukud ei saanud mõrsjalt vöid-linikuid.

valeviinad (Pär) pulmanali: soolvesi (või mõni muu taoline vedelik), mida pakuti seoses valepruudi etendamisega.

valgest tegema (Lüg) mõrsja hommikusse silmapesuvette hõberaha panema.

valget viskama või panema (Krk, Hls, Pst) 1. hõberaha (koos muude ainetega) ohverdama haiguse ravimiseks, nõiduse tõrjumiseks jne; 2. pulmades veimede eest tasumine hõberahaga (vrd vakaraha); 3. pulmades uue kodu tutvustamisel (vt uue kodu tutvustamine) annete panemine ettenähtud kohtadesse mõrsja poolt; 4. hõberaha panemine ristimisvette.

valgustama (Tor, Krk, Hel, Ksi) vt valget viskama 2 ja 3; pärast pulmaööd pidi noorik jätma asemele sukad või vöö ja pesuvee sisse panema hõberaha - see oli valgustamine.

valtsnoorik (Rap, Kul, Vig, Var, Muh, Tõs, Aud, PJg), ka kassinoorik, kukenoorik, koeranoorik, narrinoorik; 1. vt ebamõrsja ja mõrsja otsimine 2 ; 2. pulmanali, mida tehti pulmade lõpul, pärast rituaalseid talitusi: tavaliselt ehiti üks meesterahvas noorikuks, teda tutvustati pulmarahvale, pakuti valeviina (vt valeviinad), temaga parodeeriti pulmakombeid.

valtsnooriku põllepaikamine (Vig). Valtsnoorik istus, põll põlve peal lahti, üks mees istus kõrval, viinapudel käes ja kutsus pulmalisi põlle paikama; pulmanali.

valtspeigmees (Vig) pulmanali; vähem tuntud kui valtsnoorik.

valtspruut (Vig) vt valtsnoorik.

vana riiete raha (Käi) pulmanali: pärast veimede jagamist koguti suure kotiga pulmaliste käest vana riiete raha.

vanikuraha $(\mathrm{Se})$ podruskitele palgaks antav raha. 
vankritegemine (Rap, Mär) rahakogumine pulmanaljana: pulmalisi kutsutakse noorpaarile vankrit tegema: lauale pannakse paberraha vankrikereks ja hõbemüntidest pannakse rattad.

varastamine (Vig, Aud, Kus, Pöi, Krj, Ksi, TMr) väga levinud tava pulmades: lahkudes mõrsjakodunt püüdsid peiupoisid kaasa võtta igasuguseid esemeid (et mõrsja koduigatsust kustutada), valvajateks-takistajateks olid veljed; pulmasõidul püüdis ajumees mõrsjat varastada, valvajateks olid peiupoisid (kui vargus õnnestus, pidid peiupoisid mõrsja lunastama ja taluma peiu etteheiteid); kui veimekirst toodi peiukoju, siis püüti seda peiupoolsete poolt varastada, valvajateks-takistajateks olid kirstumehed või veljed (need sõidki kirstu peal, et kirstu mitte silmist lasta). Need on peamised varguseobjektid pulmades. Omaaegne maagilisrituaalne tähendus on hiljem muutunud mängulis-naljatlevaks tavaks, mille üheks eesmärgiks oli ka raha hankimine noorpaarile (varastatud asi tuli ju välja osta või lunastada).

vastastikku laulmine oli pulmades tavaline: kõiki olulisi episoode saatis laul, mõlemal poolel oli oma laulik(ud) ja omad laulud - mida üks kiitis, seda teine laitis.

veimed, ka lahjad, anded, annid, 1. pulmalistele - eeskätt saajarahvale - mõrsja poolt antavad anded (sukad, sokid, kindad jne); 2. mõrsja kaasavara; 3. riidekraam mõrsja kaasavarast. Veimed olid valmistatud mõrsja ja teiste külatüdrukute poolt (vt veimetalgud) ning kogutud oma ja naaberküladest (vt viinutamine).

veimede jagamine (Amb, Var, Tõs, Aud, Pär, Hä, Tor, Hls, Krk, Vil) reeglina toimus jagamine peiukodus, teisel pulmapäeval pärast kirstu saabumist (kas vahetult või pärast söömist); veimede jagamine oli tanutamise järel teine oluline rituaal eesti pulmakombestikus: sellega sõlmiti sidemed mõrsja ja peiu suguseltsi vahel; tava oli lokaalselt väga varieeruv: veimed tõi kirstust veimevakaga tuppa peiupoiss või pruudivend; veimi jagas isamees või mõrsja või kõrvane; veimed kas ulatati mõõga otsas või seoti saajale kaela või ümber; tänuks tantsiti kõrvasega, peiupoisiga või mõrsjaga; kombeks oli anda veimede eest raha (vt veime. mü̈̈mine). Reeglina anti veimi ainult kutsutud pulmalistele. Erandiks on nn jooksupaelad.

veimekimp (Tõs, Aud, Mih, Pär, Hää, Saa, SJn, KJn) veimekimp anti ainult peiu lähematele sugulastele, kimbus olid meestesukad, naistesukad, kindad, vöö, sukapaelad (äiale-ämmale mõeldud kimbud veel särgi või hame, salli või rätikuga). Vrd täied annid.

veimekirst (Vai, Sim, Var, Pär, Saa, SJn), ka laev, põletismustriga kaunistatud puukirst, mille sees olid veimed; tavaliselt olid need juba koondatud kimpudesse, nii et jäi ainult üleandmise $\sim$ kinkimise vaev.

veimemüümine (Vig) vt veimede jagamine; müümisega on rõhutatud veimede eest tasumise vajadust (on teateid, et pooled anded anti tasuta, kuid täied anded «maksid» kaks rubla).

veimeraha (Tõs, Pär, Hää) vt vakaraha 1 ja veimemüümine.

veimetalgud (Aud). Kui hundihänna ajamisega tuli kokku rohkesti toorainet (villu, linu, lõnga), siis korraldas mõrsja veimetalgud, kuhu tulid pruudieas külatüdrukud; kui mõrsja ema oli heasoovlik, siis tehti talgulistele ka rooga; nii valmis veimevakk ühistööga. Seegi oli üks omaaegsest vastastikuse abistamise vormidest. 
veimetants (Tõs, Krk) tants tänuks veimede saamise eest; tantsiti - veimed ümber seotud peiupoisi ja kõrvasega, harvem mõrsjaga. Vrd vakatants.

veimevakapoisid (Rap), vt vakapoisid.

veimevakk, ka annivakk, andevakk, lahjavakk; 1. metafoorselt kaasavara; 2. vt vakk 1.

veli (Lüg, Mär, Vig, Mih, Var, Han, Kse, Lih, LNg, Khn, Tõs, PJg), ka neitsiveli, pruudiveli 1. pulmategelane - mõrsjavend (kui venda ei olnud, siis noorem vallaline meessugulane), oli mõrsja saatja, kõrvase abiline; 2. peigmees laulatuseni (Har).

veljed (Vig, Han, Kse, Tõs), ka pruudiveljed - pulmategelased saunja poolt - toimetasid veimekirstu peiukoju, valvasid kirstu, tõid pulmalisi andeid saama ja raha maksma, olid tegevad pulmanaljades.

veljekann (Jõe, Var, Kse) veljede valmistatud eriti pidulik ja ehitud õllekann mõrsjapoolses pulmas (sellega viidi saabuvale pulmarongile õlut teele vastu).

veljelaud (Vig, Var, PJg) eraldi söögilaud veljedele ahju või kolde ees; sealt püüdsid teised pulmalised näpata küll viina, küll söögikraami; näppajaid tõrjuti piitsahoobiga sõrmedele (sellest olla mõnikord tõusnud tõsine riid ja tüli, sestap on tava hilisemal ajal taandunud).

vere laskmine (Kam, Võn) pulmanali raha kogumiseks (raudkäpa näitamise järgi võtsid pulmapoisid pulmalise kinni, puuväitsaga «lõigati» haav ja kuremarja mahl oli vereks vabanemiseks tuli maksta).

veskit tegema (Ksi, TMr) pulmanali.

vetsorka laud (Vas, Se) pulmalaupäeval pulmaliste saabumiseks korraldatud söömine, kummalgi poolel eraldi, selles osalesid ka need, kellel polnud võimalik pulma tulla; pärast söömist jäeti lauale raha, kasvõi paar münti.

vihtlemine (Rap, Vig, Lih, Var, Kse, KJn, Ksi, Kod, MMg, Võn) pulmanali raha kogumiseks (ehitati reest ja muust kolist lava või pandi redel ahju najale või toodi virutseküna - vt virutseküna -, sinna viidi pulmaline, vihuti kuiva vihaga, ka seoti haspli iga haru otsa viht ja vihuti sellega - vrd rattapeks; pärast vihtlemist pakuti õlut, vihtlemise eest pidi maksma).

vihtlemise masin (Rap, Kse, Aud) vokk, vankriratas või haspel, mille harude resp kodarate külge oli seotud vihad. Masinaga vihtumine maksis enam.

viinad 1. kosjad (Lüg, Juu, Tõs, Muh); 2. kihlus (Juu, Ris, Krk); 3. kuulamine (Kod); 4. kokkutulek pastorile lugema minemise hommikul (Rap).

viinad viidud (Lüg, Ris, Muh, Tõs) kosjad.

viinajoodud 1. kosjad (Lüg); 2. kihlused (Juu). 
viinajoomad (Jür, Rid) kosjad.

viinaraha (Ksi) vastastikuse abistamise tava: pulmaline maksis viinaraha (rubla-kaks) või viis kaasa vaadi õlut.

viinu jooma, ka viinul olema, viinule minema kihlusi pidama (neljapäeva õhtul käidi kosjas, reede õhtul joodi viinad, laupäeval mindi lugema, pühapäeval öeldi maha) (Rap, Juu); kuulamas käima (Kod).

viinutama 1. üldine tava: viinaga midagi korjama (õlgi, kala, kartuleid jne), peamiselt maatameestele omane; 2. mõrsja käis kosjaviinaga (Jõh, Iis, Koe, Kuu, Jür, Kos, Rap, Mär, Kul, Han, Kse, PJg, Vän, Hää, Pst, Ksi, Lai, Trm) a) sugulastele pulmadest teatamas - sai vastu andeid; b) vt hundihända ajama. Ilmselt on segunenud pulma kutsumine (millest on eristunud hundihänna ajamine) viinutamisega, mis XIX saj on muutunud üldiseks tavaks.

virutseküna, ka virutisküna, virutusküna (Mär, LNg, Mar, Vig, Lih, Tõs); ühest tüvest õõnestatud suur pesuküna, pulmas kasutatud vihtlemiseks (vt vihtlemine).

võileivamüümine (Vig) pulmanali raha kogumiseks.

võrgukudumine (Muh) pulmanali raha kogumiseks.

võtmed (Vig). Kui noorik sai kohe perenaiseks, viskas ämm põllepaikamisel taluvõtmed nooriku sülle.

võõras vägi (Vig) sissesõitnud pulmalised (peiupoolsed mõrsjakodus, mõrsjapoolsed peiukodus).

väiksed viinad üldiselt kuulamine (vt kuulamine); lokaalselt: peiu käib mõrsja vanematelt üksi luba küsimas kosja tulla (Ris) - see on kuulamise n-ö degenereerunud vorm, ebarituaalne.

vöö jagamine (Vig) toimus kohe pärast saajarongi sissesõitu - kõik sissesõitnud said vöö.

vöö-paelad (Lä) laiad mustrilised vööd, tutid otsas - levinud pulmaand.

õlemees (Kul, Tõs) õlest kuju (puukaika ümber õled) - pulmanali, oli asjade-varas ja tüdrukute tantsitaja.

õllepudi, ka õllepeergis, õllepeerike, õllepiim, õllesupp (Kad, Ann, Amb, Tür, Kei, Juu, Mär, Kul, Vig, Mih, Var, Kse, Lih, Kir, Phl, Pöi, Tõs, Saa, Hls, Äks) õllest, piimast, pulmades ülejäänud saiast-leivast (ja suhkrust) keedetud lõputoit.

õnneklimp (Pha) klimbisupi (lõputoit) keetmisel ühe klimbi sisse pandud hõbemünt; kes söögi ajal selle klimbi sai, sellel oli midagi head oodata (abielulisel lapsesünd, vallalisel abielu).

ouejooksmine (Vig, Lih) mänguline pulmanali. 
ouejooksupaelad (Vig, Var, Tõs, Aud, San) sukapaelad, mida mõrsja, veli või peiupoiss õues maha viskas, järele jooksjad kogusid paelu, kes rohkem kogus - sai mehele (või vastupidi). See toimus pärast veimede jagamist ja selles osales noorem rahvas (vallalised).

äiapoiss (Lai, Kod) pulmategelane, äia sõidutaja; saajarongis sõitis esimesena ja enne teisi teatamaks teisele poolele, et pulmad tulevad (isamees on teisel kohal, peigmees kolmandal).

ämmakaasik (Kod) pulmategelane, mõrsja ema saatja (üks pruuttüdrukutest).

ämmakakk (Iis) kakk või kook, mis pulma ajal saadetakse ämmale (saajarongiga mõrsja emale, pulmarongiga peiuemale).

ämma noorikuks tegemine (Rap) pulmanali - kui noorik valmis, siis istus ämm toolile ja seegi tehti ehiti noorikuks: minia antud müts pähe ja põll ette.

ämma põlle paikamine (Trm) pulmanali raha kogumiseks.

ämmapütt (Trv, Kod, Äks) vt järelpulm; nädal pärast pulmi läksid ligemad sugulased pruudikoju ämmapütile; nädal hiljem peiukoju - siis tuli ka mõrsja ema, kes tavaliselt varem ei olnud peiukodus käinudki; oli tavaks, et noorpaarile võis külla minna alles siis, kui ämmapütt oli peetud.

ämmavaat (Kod) vt ämmapütt.

öntamas käima (Jõe) vt viinutama.

ühe otsaga pulmad $(\mathrm{Sa})$ ainult peiukodus peetavad pulmad, üldine Saaremaal.

ühe pere pulmad (Ris) vt ühe otsaga pulmad.

ühel pool pulmad (Ha) vt ühe otsaga pulmad, vaesuse tunnismärk.

üle aasta omaksed (Sa) pruut-peigmees; Saaremaal oli kosjade ja pulmade vahe ligi aasta.

ülesse laulmine (Kos) noorpaar lauldi hommikul üles; hilisem tava.

üsä sukad (Ote) sülepoisile kingitavad sukad. 